\title{
Gall bladder emptying in severe idiopathic constipation
}

\author{
C Penning, H A J Gielkens, J B V M Delemarre, C B H W Lamers, A A M Masclee
}

\begin{abstract}
Background-It has been suggested that slow transit constipation (STC) may be part of a panenteric motor disorder. Aim-To evaluate motility of an upper gastrointestinal organ, the gall bladder, in 16 patients with STC and 20 healthy controls.

Methods-Gall bladder emptying (ultrasonography) was studied in response to neural, cephalic-vagal stimulation with modified sham feeding (MSF) for $90 \mathrm{~min}$ utes and in response to hormonal stimulation with cholecystokinin (CCK, 0.5 IDU/ $\mathrm{kg} / \mathrm{h}$ ) for 60 minutes.

Results-Fasting gall bladder volume in patients with STC (17 (2) $\left.\mathrm{cm}^{3}\right)$ was significantly $(p<0.01)$ reduced compared with that in controls $\left(24(2) \mathrm{cm}^{3}\right)$. Gall bladder emptying in response to MSF was significantly reduced in patients with STC expressed both as percentage emptying (11 $(5) \%$ versus $22(3) \% ; p<0.05)$ and as absolute emptying $\left(2.1(0.7) \mathrm{cm}^{3}\right.$ versus 4.9 (0.7) $\left.\mathrm{cm}^{3} ; \mathrm{p}<0.02\right)$. However, percentage gall bladder emptying in response to CCK was not different between patients and controls (73 (4)\% versus $67(4) \%)$ although the absolute reduction in gall bladder volume was significantly $(p<0.05)$ smaller in patients $\left(10.7(1.1) \mathrm{cm}^{3}\right.$ versus $\left.15.3(1.4) \mathrm{cm}^{3}\right)$. Conclusions-Patients with slow transit constipation have smaller fasting gall bladder volumes, impaired gall bladder responses to vagal cholinergic stimulation, but normal gall bladder responses to hormonal stimulation with CCK. These results point to abnormalities in gastrointestinal motility proximal from the colon in slow transit constipation and more specifically, impaired neural responsiveness.

(Gut 1999;45:264-268)
\end{abstract}

Keywords: slow transit constipation; gall bladder emptying; sham feeding; cholecystokinin

Patients with severe chronic constipation can be subdivided into those with outlet obstruction, those with slow transit constipation (STC), and those with normal transit constipation. ${ }^{1}$ In case of long term persistence of STC and failure of conventional drug treatment, (sub)total colectomy is considered. However, the value of surgery in these patients has been questioned as symptoms of delayed transit persist in a considerable number of patients after (sub)total colectomy. ${ }^{2-8}$ Therefore it has been suggested that, apart from alterations in colonic function, proximal gastrointestinal function might be abnormal as well. Recently it has been hypothesised that chronic constipation is part of a more generalised gastrointestinal motility disorder. ${ }^{8}$ Alterations in small bowel motility, ${ }^{9-11}$ gastric emptying, ${ }^{911}$ and gastrointestinal hormone release $^{12}$ have been described and support the concept that severe idiopathic constipation may be part of a panenteric disorder.

To investigate this hypothesis further, we have studied whether gall bladder emptying is abnormal in severely constipated patients with slow colonic transit when compared with healthy controls. Gall bladder motor function can be assessed non-invasively by ultrasonography. As constipation has been associated with autonomic neuropathy, ${ }^{10} 13$ gall bladder emptying was studied in response to vagal cholinergic stimulation with modified sham feeding. In addition, the gall bladder response to cholecystokinin, an important hormonal mediator of gall bladder contraction, ${ }^{15}$ was evaluated.

\section{Patients and methods}

SUBJECTS

Severe chronic idiopathic constipation was defined by a stool frequency of two times per week or less, persistent for at least 12 months. Patients with outlet obstruction or organic pathology were excluded, as well as patients who had previously undergone abdominal surgery. According to these criteria, a total number of 16 patients with constipation were included. The patient group consisted of 15 women and one man with a mean age of 39 (SEM 3) years and a mean body mass index (BMI) of $22(0.6) \mathrm{kg} / \mathrm{m}^{2}$. All patients had a long standing history of severe constipation, with an average duration of 7 (2) years. They regularly used oral laxatives or enemas.

Large bowel transit was determined according to the method of Wald. ${ }^{16}$ Colonic transit was considered delayed when the residual number of ingested radio-opaque markers visualised in the colon on day 5 after ingestion, was $20 \%$ or more of the 50 ingested markers. According to this criterion, all 16 patients had STC. Mean large bowel transit time in the patients was 111 (4) hours.

Twenty healthy volunteers, comprising 15 women and five men with a mean BMI of 22 (0.3) $\mathrm{kg} / \mathrm{m}^{2}$ and a mean age of 37 (3) years, served as controls. None of the control subjects was on medication or had a relevant medical

Abbreviations used in this paper: $\mathrm{BMI}$, body mass index; CCK, cholecystokinin; DCA, deoxycholic acid; MSF, modified sham feeding; PYY, peptide YY; STC, slow transit constipation. 
history. None of them had a history of constipation or diarrhoea. Stool frequency was once daily. Mean large bowel transit time in the control group was 37 (3) hours.

All subjects gave informed consent and the study protocol was approved by the local human ethics committee. Patients with constipation were instructed to stop any medication interfering with gastrointestinal motility at least three days before the test. They were instructed to defaecate, if necessary with the use of enemas, on the day prior to the measurements.

\section{STUDY DESIGN}

Gall bladder emptying was studied in response to a cephalic vagal and a hormonal stimulus. The cephalic phase of digestion was induced by modified sham feeding (MSF) according to the "chew and spit" method. ${ }^{17}$ As the response of the gall bladder to sham feeding is abolished by intravenous atropine or vagotomy, ${ }^{18-20}$ sham feeding is thought to stimulate through vagal cholinergic neural pathways. In addition, the response of the gall bladder to intravenous infusion with cholecystokinin (CCK) was examined, as this hormone is the most potent hormonal mediator of gall bladder contraction. ${ }^{15}$

Subjects were studied after an overnight fast and arrived at our department at 800 am. Intravenous catheters were inserted into the antecubital veins of both forearms. One cannula was used for blood sampling, the other for hormone infusion. Gall bladder images using ultrasonography were obtained every 15 minutes from time $t=-15$ to +150 minutes and blood samples for plasma CCK every $30 \mathrm{~min}$ utes from time $\mathrm{t}=-15$ and $\mathrm{t}=0$ to +150 minutes. At time $t=0$ minutes, subjects were offered a standard MSF meal, which consisted of a slice of brown bread, $10 \mathrm{~g}$ margarine, a slice of cheese, a slice of meat, $30 \mathrm{~g}$ marmalade, and a boiled egg. According to the "chew and spit" technique, subjects were allowed to smell, chew, and taste the items of preference, but were explicitly instructed not to swallow a single morsel of food. After the first 15 minutes subjects were provided with a new, identical MSF meal and the procedure was continued for another 15 minutes until time $t=30$ minutes. At time $\mathrm{t}=90$ minutes, intravenous infusion with CCK (Ferring Pharmaceuticals, Malmö, Sweden) was started at a rate of 0.5 Ivy Dog Units (IDU) per kilogram body weight per hour. Previous studies have shown that using this dose, plasma CCK concentrations comparable to postprandial concentrations are reached. ${ }^{21}$ After an hour of CCK infusion, the test was stopped.

GALL BLADDER VOLUMES

Gall bladder volumes measured by real time ultrasonography (Technicare, $3.5 \mathrm{MHz}$ transducer) were calculated by the sum of cylinders method using a computerised system. As previously described, this method divides the longitudinal image of the gall bladder into cylinders of equal height, with diameters perpendicular to the longitudinal axis of the gall bladder image. ${ }^{22}$ The uncorrected volume is the sum of volumes of these distinct cylinders. A correction factor is calculated from the longitudinal and transversal images of the gall bladder, in order to correct for the displacement of the longitudinal image of the gall bladder from the central axis. By multiplication of the uncorrected volume with the square of the correction factor, the corrected gall bladder volume is calculated.

Absolute $\left(\mathrm{cm}^{3}\right)$ gall bladder emptying induced by MSF and CCK infusion was calculated by subtracting gall bladder volumes measured at time $t=30$ and $t=150$ minutes from gall bladder volumes measured at time $\mathrm{t}=0$ and $\mathrm{t}=90$ minutes respectively. The gall bladder response to MSF was measured at time $\mathrm{t}=30$ minutes as its effect is most pronounced in the first 60 minutes. ${ }^{20}$ The percentage gall bladder emptying was calculated using the gall bladder volumes at time $\mathrm{t}=0$ and $\mathrm{t}=90$ minutes as reference value $(100 \%)$.

\section{PLASMA CCK}

Immediately after sampling, blood samples were centrifuged for 15 minutes at $3000 \mathrm{rpm}$ at a constant temperature of $4^{\circ} \mathrm{C}$. Until CCK concentrations were determined, plasma samples were stored at $-20^{\circ} \mathrm{C}$. Plasma CCK concentrations were measured by a sensitive and specific radioimmunoassay (RIA) using antibody $\mathrm{T}_{204}$, as described previously. ${ }^{23}$

\section{STATISTICAL ANALYSIS}

Results are expressed as mean (SEM). Statistical comparisons for gall bladder emptying induced by MSF and CCK were made using the non-parametric Wilcoxon rank sum test or, where appropriate, Student's $t$ test for unpaired data. Variations of gall bladder volumes over time were statistically compared by means of analysis of variance (ANOVA). The level of significance was set at $\mathrm{p}<0.05$.

\section{Results}

GALL BLADDER EMPTYING

Figure 1 and table 1 depict the results of gall bladder emptying. Mean fasting gall bladder volume, measured at time $t=0$ minutes, was significantly smaller in the patients with STC than in the controls (figs 1 and 2). In the controls, gall bladder volumes decreased significantly in response to MSF. The reduction in gall bladder volume after MSF in the patients with STC was also statistically significant. Figure 3 depicts individual and mean data of absolute gall bladder emptying in response to MSF. Absolute gall bladder emptying in response to MSF was significantly lower in patients with STC. The percentage gall bladder emptying induced by MSF was also significantly reduced in the patients with STC (table 1).

Cholecystokinin induced a significant decrease in gall bladder volume both in controls and in patients. Figure 4 depicts individual data and mean of absolute gall bladder emptying in response to CCK. Absolute gall bladder emptying induced by CCK was significantly reduced in the patient group. However, the percentage volume reduction was not significantly different (table 1). Residual gall bladder volumes at the end of CCK infusion were significantly lower in patients with STC than in controls. 
Table 1 Gall bladder motility in 20 control subjects and 16 patients with slow transit constipation (STC)

\begin{tabular}{lrrl}
\hline & \multicolumn{1}{l}{ Controls } & \multicolumn{1}{l}{ STC } & Significance \\
\hline Fasting gall bladder volume $\left(\mathrm{cm}^{3}\right)$ & $23.8(1.5)$ & $17.2(1.7)$ & $\mathrm{p}<0.01$ \\
Modified sham feeding & & & \\
$\quad$ Gall bladder emptying at 30 $\mathrm{min}\left(\mathrm{cm}^{3}\right)$ & $4.9(0.7)$ & $2.1(0.7)$ & $\mathrm{p}<0.02$ \\
$\quad$ Gall bladder emptying at 30 min $(\%)$ & $21.7(3.0)$ & $11.1(4.9)$ & $\mathrm{p}<0.05$ \\
Cholecystokinin & $15.3(1.4)$ & $10.7(1.1)$ & $\mathrm{p}<0.05$ \\
$\quad$ Gall bladder emptying after $60 \mathrm{~min}\left(\mathrm{~cm}^{3}\right)$ & $67.3(3.5)$ & $72.6(4.4)$ & $\mathrm{NS}$ \\
$\quad$ Gall bladder emptying after $60 \mathrm{~min}(\%)$ & $7.5(1.0)$ & $3.5(0.4)$ & $\mathrm{p}<0.01$ \\
$\quad$ Residual volume $\left(\mathrm{cm}^{3}\right)$ & & & \\
\hline
\end{tabular}

Results are expressed as mean (SEM).

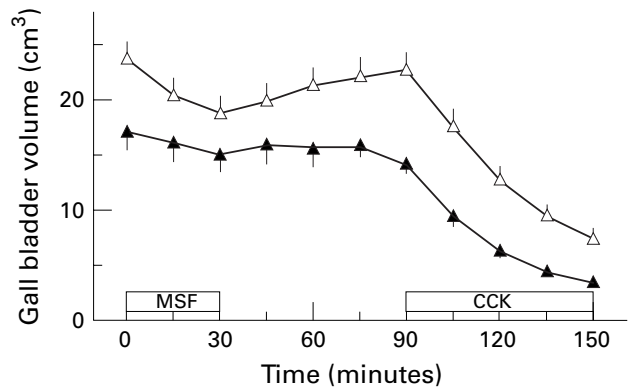

Figure 1 Gall bladder volumes (mean (SEM)) in the fasting state, during, and after modified sham feeding (MSF) and in response to cholecystokinin (CCK) infusion in controls (open triangles) and patients with slow transit constipation (STC; closed triangles).

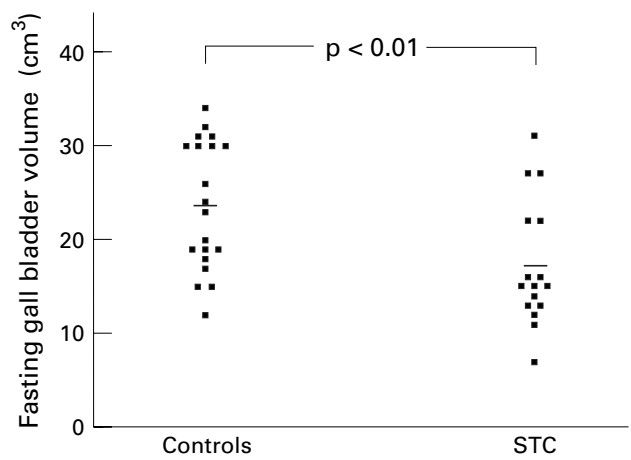

Figure 2 Individual data and mean of fasting gall bladder volumes $\left(\mathrm{cm}^{3}\right)$ in controls and patients with slow transit constipation (STC). Means are represented by horizontal bars.

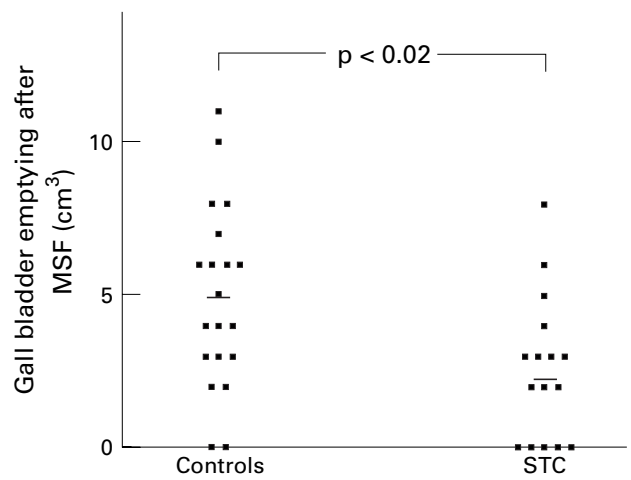

Figure 3 Individual data and mean of absolute gall bladder emptying $\left(\mathrm{cm}^{3}\right)$ induced by modified sham feeding $(M S F)$ in controls and patients with slow transit constipation (STC). Means are represented by horizontal bars.

PLASMA CCK

Fasting plasma CCK concentrations were not significantly different between patients (1.7 (0.2) $\mathrm{pM}$ ) and controls (2.0 (0.1) pM). As expected, during and after MSF, no alterations

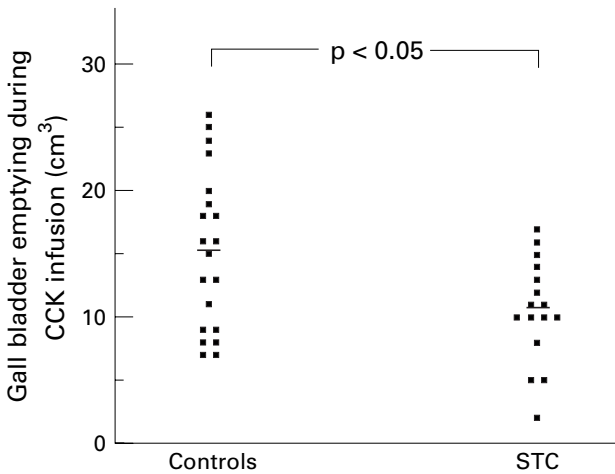

Figure 4 Individual data and mean of absolute gall bladder emptying induced by cholecystokinin (CCK) in controls and patients with slow transit constipation (STC). Means are represented by horizontal bars.

in plasma CCK were observed. During CCK infusion from time $\mathrm{t}=90$ to $\mathrm{t}=150$ minutes, plasma CCK concentrations increased from $1.7(0.2) \mathrm{pM}$ to $4.5(0.2) \mathrm{pM}$ in the patient group, and from $2.0(0.2) \mathrm{pM}$ to $4.7(0.3) \mathrm{pM}$ in the control group (NS).

\section{Discussion}

Our results show that gall bladder emptying in patients with STC is different from that in age matched healthy controls.

In patients with STC, mean fasting gall bladder volume was significantly reduced. Several factors are known to influence fasting gall bladder volume. Firstly, CCK is involved not only in the regulation of postprandial gall bladder contraction but also of fasting gall bladder volume. During CCK receptor blockade gall bladder volume increases significantly. ${ }^{24}$ Fasting plasma CCK concentrations in the patients with STC were not significantly different from those in control subjects, thereby excluding a role for CCK in the smaller fasting gall bladder volumes in these patients. Secondly, the distal gut hormone peptide YY (PYY) induces relaxation of the gall bladder. ${ }^{25}$ In patients with severe idiopathic constipation reduced plasma PYY concentrations have been found ${ }^{26}$ and may account for the reduction in fasting gall bladder volume. Thirdly, gall bladder volume is correlated to body mass. A correlation between individual BMI and fasting gall bladder volume has recently been described: a high BMI is correlated with increased basal gall bladder volume. ${ }^{27}$ However, BMI in our patients with STC was not different from controls. Gall bladder tone is also regulated by vagal cholinergic input. After truncal vagotomy or during vagal cholinergic blockade with atropine, gall bladder volume increases. ${ }^{20}$ On the other hand, during vagal cholinergic stimulation gall bladder contraction occurs. ${ }^{28}$ Therefore, the small fasting gall bladder volume of patients with STC might be ascribed to increased vagal tone. However, this is unlikely because recent studies indicate that STC may be associated with autonomic neuropathy.

Indeed, compared with controls, gall bladder contraction in response to MSF was significantly reduced in patients with STC, pointing to impaired vagal cholinergic transmission. Our results are in line with recent findings from 
Altomare $e t a l^{13}$ who found abnormal results of the acetylcholine sweat spot test in patients with STC, pointing to parasympathetic autonomic neuropathy. Another explanation for the impaired response of the gall bladder to MSF might be alterations of the intramural plexus of the gall bladder, which receives its neuronal input from the vagus nerve. Krishnamurthy et $a l^{29}$ and Schouten et $a l^{14}$ have described abnormalities of the colonic myenteric plexus in severe idiopathic constipation. Assuming that in some cases STC might be a systemic disorder, abnormalities of the myenteric plexuses might be more diffusely spread. According to the present study protocol, no differentiation between impaired vagal responsiveness or intrinsic alterations could be made. An increased gall bladder contraction after MSF in the control group was certainly not due to unintentional swallowing of food particles, because plasma CCK did not increase over basal during MSF.

During CCK infusion, gall bladder volumes decreased significantly both in patients and controls. When comparing both groups, the percentage emptying was not different, but the absolute reduction in volume was significantly smaller in patients with STC. Our results partly contrast with findings from two other studies. Neri et al found a stronger gall bladder contraction in patients with STC during intravenous infusion with stepwise increasing doses of the CCK analogue caerulein. ${ }^{30}$ Another recent study described impaired gall bladder contraction during CCK infusion in patients with STC. ${ }^{31}$ The discrepancy in results between our study and those of Neri et al and Hemingway et al may be related to patient selection, measurement techniques (scintigraphy versus ultrasonography), or infusion of CCK (bolus versus continuous) which might result in different plasma CCK concentrations. In the study of Neri et al group size was rather small $(n=6)$, infusion rates of CCK were increased every five minutes, and plasma CCK concentrations were not determined. In the study of Hemingway et al gall bladder contraction was measured by cholescintigraphy and very high, supraphysiological, doses of CCK were used.

The clinical significance of the present findings is uncertain because we have not evaluated postprandial gall bladder emptying. Apart from neural stimuli and the responsiveness of the gall bladder to CCK, other factors such as the rate of gastric emptying or the amount of endogenous CCK release contribute to postprandial gall bladder emptying.

It is not known whether the incidence of gallstones is higher in patients with STC. Recently an association has been reported between slow intestinal transit and cholesterol gallstones. ${ }^{32}$ Although we did not measure meal stimulated gall bladder emptying in the present study, we showed that the ejection fraction in response to CCK infusion was not altered in patients with STC. In patients with cholesterol gallstones however, postprandial gall bladder emptying is impaired, ${ }^{33}$ resulting in an increased residual volume. Apart from gall bladder motility, increased biliary deoxycholic acid (DCA), which is associated with increased biliary cholesterol saturation, is also a risk factor for the development of cholesterol gallstones. ${ }^{34}{ }^{35} \mathrm{Sec}-$ ondary to delayed intestinal transit, the circulating bile acid pool might increase in patients with STC, probably resulting in increased biliary DCA concentrations. ${ }^{34}{ }^{36}$ Increased biliary DCA concentrations secondary to delayed bowel transit may contribute to gallstone disease in these patients. In addition, biliary DCA may directly affect gall bladder motility: long term suppletion of bile acids in gallstone patients for example, increases biliary DCA concentrations and is associated with increased fasting gall bladder volume ${ }^{37} 38$ and with impaired postprandial gall bladder emptying. ${ }^{38-40}$ Our results point to smaller instead of larger fasting gall bladder volumes in patients with STC, and meal induced gall bladder emptying was not assessed.

In conclusion, gall bladder emptying is affected in patients with STC. Mean fasting gall bladder volume is significantly reduced, as well as the response to a vagal cephalic stimulus, pointing to visceral neuropathy. Our results suggest that apart from the colon, the function of proximal gastrointestinal organs such as the gall bladder is also affected in STC. It is questioned whether these alterations are part of a more generalised intestinal motor disorder.

1 Wald A. Colonic transit and anorectal manometry in chronic idiopathic constipation. Arch Intern Med 1986;146:171316

2 Piccirillo MF, Reissman P, Wexner SD. Colectomy as treatment for constipation. Gastroenterology 1996;110:1666-71 3 Lubowski DZ, Chen FC, Kennedy ML, et al. Results of colectomy for severe slow transit constipation. Dis Colon Rectum 1996;39:23-9.

4 Kamm MA, Hawley PR, Lennard-Jones JE. Outcome of colectomy for severe idiopathic constipation. Gut 1988;29: 969-73.

5 Leon SH, Krishnamurthy S, Schuffler MD. Subtotal colectomy for severe idiopathic constipation: a follow-up study of 13 patients. Dig Dis Sci 1987;32:1249-54.

6 Preston DM, Hawley PR, Lennard-Jones JE, et al. Results of colectomy for severe idiopathic constipation in women colectomy for severe idiopathic constipation in wom
(Arbuthnot Lane's disease). Br f Surg 1984;71:547-52.

7 Wexner SD, Daniel N, Jagelman DG. Colectomy for constipation: physiologic investigation is the key to success. Constipation: physiologic investigat

8 Redmond JM, Smith GW, Barofsky I, et al. Physiological tests to predict long-term outcome of total abdominal colectomy for intractable constipation. Am $\mathcal{F}$ Gastroenterol 1995;90:748-53.

9 Coremans G, Wilmer A, Andrioli A, et al. Slow transit constipation is associated with delayed gastric emptying and impaired small bowel motility [abstract]. Neurogastroenterol Motil 1995; 7:252.

10 Bassotti G, Stanghellini V, Chiaroni G, et al. Upper gastrointestinal motor activity in patients with slow-transit constipation: further evidence for an enteric neuropathy. Dig Dis Sci 1996;41:1999-2005.

11 van der Sijp JRM, Kamm MA, Nightingale JMD, et al. Disturbed gastric and small bowel transit in severe idiopathic constipation. Dig Dis Sci 1993;38:837-44.

12 Sjölund K, Ekman R, Akre F, et al. Motilin in chronic idiopathic constipation. Scand f Gastroenterol 1986;21:914-18. pathic constipation. Scand f Gastroenterol 1986;21:914-18.
Altomare D, Pilot MA, Williams N, et al. Detection of subclinical autonomic neuropathy in constipated patients clinical autonomic neuropathy in cons

14 Schouten WR, ten Kate FJW, de Graaf EJR, et al. Visceral neuropathy in slow transit constipation: an immunohistochemical investigation with monoclonal antibodies against neurofilament. Dis Colon Rectum 1993;36:1112-17.

15 Masclee AAM, Jansen JBMJ, Driessen WM, et al. Plasma cholecystokinin and gallbladder responses to intraduodenal fat in gallstone patients. Dig Dis Sci 1989;34:353-9.

16 Arhan P, Devroede G, Jehannin B, et al. Segmental colonic transit time. Dis Colon Rectum 1981;24:625-9.

17 Schwartz TW, Stenquist B, Olbe L. Cephalic phase of pancreatic polypeptide secretion studied by sham feeding in man. Scand f Gastroenterol 1979;14:313-20.

18 Hopman WPM, Jansen JBMJ, Rosenbusch G, et al. Cephalic stimulation of gallbladder contraction in humans: role of cholecystokinin and the cholinergic system. Digestion 1987;38:197-203.

19 Ihasz M, Griffith CA. Gallstones after vagotomy. Am f Surg 1981;141:48-50. 
20 Fisher RS, Rock E, Malmud LS. Gallbladder emptying response to sham feeding in humans. Gastroenterology

21 Hopman WPM, Kerstens PJ, Jansen JBMJ, et al. Effect of graded physiologic doses of cholecystokinin on gallbladder contraction measured by ultrasonography. Determination of threshold, dose-response relationships and comparison
with intraduodenal bilirubin output. Gastroenterology 1985; with intradu:

22 Hopman WPM, Brouwer WFM, Rosenbusch G, et al. A computerized method for rapid quantification of gallbladder volume from real-time sonograms. Radiology 1985;154: 236-7.

23 Jansen JBMJ, Lamers CBHW. Radioimmunoassay of cholecystokinin in human tissue and plasma. Clin Chim Acto 1983;131:305-16.

24 Jebbink MCW, Masclee AAM, van der Kleij FG, et al. Effect of loxiglumide and atropine on erythromycin-induced reduction in gallbladder volume in human subjects. Hepatology 1992;16:937-42.

25 Conter RL, Roslyn JL, Taylor IL. Effects of peptide YY on gallbladder motility. Am f Physiol 1987;252:G736-41.

26 van der Sijp JRM, Kamm MA, Nightingale JMD, et al. Cirvan der Sijp JRM, Kamm MA, Nightingale JMD, et al. Cir-
culating gastrointestinal hormones abnormalities in patients with severe idiopathic constipation. Am $\mathcal{F}$ Gastroenterol 1998;93:1351-6.

27 Masclee AAM, Gielkens HAJ, Lieverse RJ, et al. Gallbladder motility in response to sham feeding and cholecystokinin in lean and obese subjects. Digestion 1997;58:43-9.

28 Tierney S, Pitt HA, Lillemoe KD. Physiology and pathophysiology of gallbladder motility. Surg Clin North Am 1993;73:1267-90.

29 Krishnamurthy S, Schuffler MD, Rohrmann CA, et al Severe idiopathic constipation is associated with a distinctive abnormality of the colonic myenteric plexus. Gastroenterology 1985;88:26-34.
30 Neri M, Schiavone C, Grossi E, et al. Gallbladder motility in slow-transit constipation: evidences toward a generalized
motility disorder [abstract]. Gastroenterology 1993;104 A558.

31 Hemingway DM, Neilly JB, Finlay IG. Biliary dyskinesia in idiopathic slow-transit constipation. Dis Colon Rectum 1996;39:1303-7.

32 Heaton KW, Emmett PM, Symes CL, et al. An explanation for gallstones in normal-weight women: slow intestinal transit. Lancet 1993;341:8-10.

33 Jazrawi RP, Pazzi P, Petroni ML, et al. Postprandial gallbladder motor function: refilling and turnover of bile in health and in cholelithiasis. Gastroenterology 1995;109:582-91.

34 Marcus SN, Heaton KW. Intestinal transit, deoxycholic acid and the cholesterol saturation of bile-three inter-related factors. Gut 1986;27:550-8.

35 Shoda J, He BF, Tanaka N, et al. Increase of deoxycholate in supersaturated bile of patients with cholesterol gallstone disease and its correlation with de novo syntheses of cholesterol and bile acids in liver, gallbladder emptying and small intestinal transit. Hepatology 1995;21:1291-302.

36 Dowling RH, Veysey MJ, Pereira SP, et al. Role of intestinal transit in the pathogenesis of gallbladder stones. Can $\mathcal{F}$

37 van Erpecum KJ, van Berge-Henegouwen GP, Stolk MFJ, et al. Effects of ursodeoxycholic acid on gallbladder contraction and cholecystokinin release in gallstone patients and

38 Festi D, Frabboni R, Bazzoli F, et al. Gallbladder motility in cholesterol gallstone disease. Gastroenterology 1990;99: 1779-85.

39 Sylwestrowicz TA, Shaffer EA. Gallbladder function during gallstone dissolution. Gastroenterology 1988;95:740-8.

40 Forgacs IC, Maisey MN, Murphy GM, et al. Influence of gallstones and ursodeoxycholic acid therapy on gallbladder emptying. Gastroenterology 1984;87:299-307. 